\title{
Durable maintenance of behavior during concurrent avoidance and punished-extinction conditions'
}

\author{
JACK SAMDLER, ROBERT S. DAVIDSON AND ED MALAGODI
}

V. A. HOSPITAL, CORAL GABLES, FLORIDA

Following complete suppression of avoidance responding during severe punishment, four marmoset monkeys were retrained and exposed to gradually increasing punishment intensities. After response rates stabilized, each session was divided into equally frequent, but mixed, unpunishedavoidance trials and punished-extinction trials. The number of punished-extinction trials was increased through two steps to a maximum. No evidence of extinction obtained until the avoidance contingency was completely withdrawn.

Punishment of bar-press avoidance behavior generally results in response facilitation, regardless of whether the punishment is response contingent or random, introduced during training or extinction or the avoidance contingency is of the Sidman or signal variety (Sidman et al, 1957; Sidman, 1958; Appel, 1960; Sandler et al, 1966a; Sandler, 1966b).

While this effect is often only temporary, procedures can be employed which maintain such responding. The present study describes the maintenance of punished, bar-press avoidance behavior over a relatively long period by means of gradual exposure to punishment during training, and by randomly alternating punishedextinction and unpunished-acquisition trials within sessions, thus reducing the discriminability of the two contingencies.

\section{Method}

Four naive male marmoset monkeys served as Ss. The apparatus was an operant conditioning chamber enclosed in a light-proof, sound-attenuating compartment. A bar extended $2.5 \mathrm{~cm}$ into the chamber and a 25 gm downward force moved the bar closing a microswitch and enabling avoidance of a shock delivered through the grid floor of the chamber. A more detailed description of the apparatus has been given elsewhere (Sandler, 1966a).

Each $S$ was trained to bar press to an audible 5 sec. tone, the termination of which was followed by a .30 sec. shock of $1.6 \mathrm{ma}$. A response during the tone interrupted the tone and avoided the shock. Each daily session involved 100 tone-shock trials with time between trials varying from 18 to $42 \mathrm{sec}$, a round a mean of 30 sec. Training continued until all Ss were functioning at a $90 \%$ or better avoidance rate and variability in total bar-press rate was reduced to less than $5 \%$ through five consecutive sessions. Each response was then punished by a shock equal in intensity and duration to the avoidance shock (100\% punishment). After avoidance responding completely ceased, the animals were retrained without punishment. When previous avoidance baselines were reattained, punishment was again intro- duced. On this occasion, however, the punishment was first presented at a mild intensity (25\% of the avoidance shock intensity, .40 ma) and subsequently increased to $50 \%$ and $75 \%$ of the avoidance shock intensity. Each new punishment condition was maintained until bar-press and avoidance rates stabilized as before.

In the next phase, the punishment was raised to $100 \%$ (1.6 ma) and each session was divided into 50 unpunished-avoidance trials, and 50 punished-extinction trials, presented at random. Thus, in each session, the tone continued to introduce each trial, but in half the trials, the avoidance shock was retained and the punishment withdrawn (Un-Av) and, in the other half, the punishment was retained and the avoidance shock withdrawn (Pun-Ex). Each animal was, therefore, required to discriminate between the two conditions, responding during Un-Av and not responding during Pun$E x$ in order to achieve maximum avoidance efficiency. However, each session was divided into equally frequent, but randomly alternating sequences of the two conditions, consisting of two to eight trials per sequence. This reduced the probability that $S$ would make the required discrimination. Furthermore, since punishment was now absent on half the trials (during Un-Av) it was assumed that this would also facilitate responding during the Pun-Ex trials, despite the increase in punishment to a maximum.

After it appeared that a steady state had been achieved, the number of Pun-Ex trials was increased to 75 per session, thereby decreasing the number of Un-Av trials to 25. The same random sequence of conditions was maintained, but the number of Pun-Ex sequences was more frequent. In the final stage of the experiment, the number of Pun-Ex trials was increased to 100 (no Un-Av trials). Each animal was run until one session elapsed in which no avoidance responses occurred.

Table 1. Mean bar press and avoidance rates during baseline training. $100 \%$ punishment training, and the third phase of the second punishment condition $(75 \%$ punishment)

\begin{tabular}{|c|c|c|c|c|c|c|}
\hline \multirow[t]{2}{*}{ Condition } & \multicolumn{2}{|c|}{$\begin{array}{l}\text { Baseline } \\
\text { Avoidance } \\
\text { Training }\end{array}$} & \multicolumn{2}{|c|}{$\begin{array}{c}\text { Punished } \\
\text { Avoidance } \\
\text { Training (700\%) }\end{array}$} & \multicolumn{2}{|c|}{$\begin{array}{c}\text { Punished } \\
\text { Avoidance } \\
\text { Retroining }(75 \%)\end{array}$} \\
\hline & Mean & S. D. & Mean & S. D. & Mean & S. D. \\
\hline \multicolumn{7}{|l|}{ Total No. } \\
\hline $\begin{array}{l}\text { BarPresses } \\
\text { Avoidance }\end{array}$ & 107.2 & 2.94 & 62.6 & 18.48 & 104.0 & 3.81 \\
\hline Percent & 39.2 & .34 & 7.7 & 2.35 & 35.9 & 4. 18 \\
\hline
\end{tabular}

$a$ The data are calculated from the last 5 training sessions, all $100 \%$ punishment training sessions to complete avoidance response suppression (mean $=2.25$, range $=2-3$ ) and the last $575 \%$ punis $h$ ment retraining sessions. 

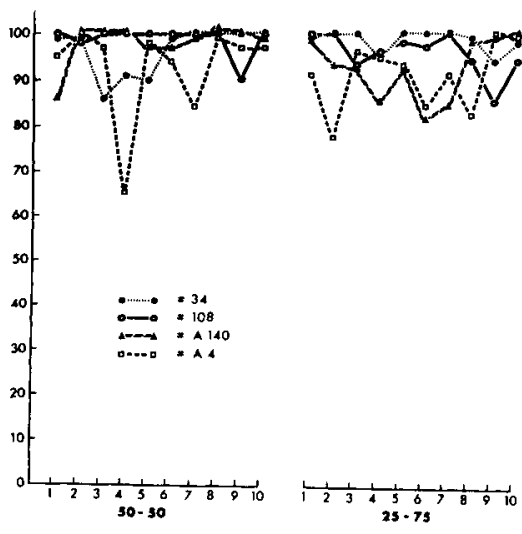

SESSION

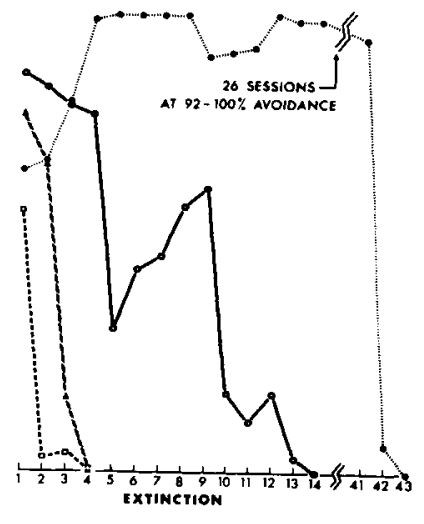

Fig. 1. Avoidance rates (Pun-Ex trials) for eacn animal during the last 10 sessions of the two mixed Un-Av, Pun-Ex phases and for all sessions of the final extinction phase.

\section{Results}

The results of the first training and punishment phases, and the final stage of punishment (under $75 \%$ punishment intensity) after retraining are summarized in Table 1. Responding was rapidly suppressed during the first punishment condition. All four animals had stopped responding by the third session of this phase. They were then retrained to baseline levels and exposed to gradually increasing punishment intensities. The maintenance of high avoidance rates, even under relatively intense punishment, indicates that the use of the above procedure did not disrupt avoidance behavior.

Table 2 depicts the results of the mixed UnAv, PunEx sessions. No decrement in performance occurred during the first phase in which the trials were equally, but randomly, distributed between the two conditions. In addition, no difference in avoidance rates between the two conditions was observed. Increasing the number of PunEx trials per session resulted in some decrease in avoidance performance. Once again, however, no evidence of extinction was observed. Results of the final phase are more ambiguous. Two animals extinguished rapidly, one continued responding through 12 sessions, while the fourth responded at a high rate through 40 sessions and then extinguished rapidly.

These findings are graphically presented in Fig. 1. The first two panels show the Pun-Ex trials avoidance curves for each $S$ during the last 10 sessions of the two mixed UnAv-PunEx phases. The third panel presents

Table 2. Mean bar-press and avoidance rates during the mixed Unpunished-Avoidance, Punished-Extinction trials sessions.

\section{No. of}

\begin{tabular}{|c|c|c|c|c|c|c|c|c|c|c|}
\hline $\begin{array}{l}\text { No. of } \\
\text { Pun-Ex Trials }\end{array}$ & \multicolumn{4}{|c|}{50} & \multicolumn{4}{|c|}{75} & & \\
\hline \multirow[t]{2}{*}{ Condition } & & Av & Pur & $-E_{x}$ & $U_{n}$ & & Pur & $-E x$ & & $n-E_{x}$ \\
\hline & Mn & SD & $M n$ & SD & $\mathrm{Mn}$ & SD & $\mathrm{Mn}$ & SD & $\mathrm{Mn}$ & SD \\
\hline
\end{tabular}

Total No.

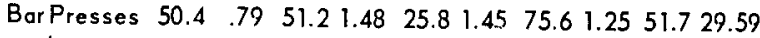
Avoidance

Percent $\quad 95.72 .65 \quad 96.72 .47 \quad 91.97 .90 \quad 95.43 .72 \quad 47.829 .75$

$a$ The data are calculated from all sessions under each condition. Mean no. of sessions during first extinction phase $=16.5$, tange $=$ 15 to 20; during second extinction phase, mean $=11.3$, range $=10$ to 14: during final extinction phase, mean $=16.0$, range $=4$ to 43 . avoidance percentages for all sessions during the final extinction phase. No evidence of extinction was observed in the first phase over an average of 16.50 sessions (mean $=825$ PunEx trials). Similar results obtained during the second PunEx phase, despite the increase in PunEx trials (mean $=847.50$ PunEx trials). One surprising result during the final extinction phase was the increase in response rate which occurred in the cases of No. 34 and No. 108. This, apparently, was responsible for the relatively high resistance to punished extinction in both animals. Analysis of the records revealed that these two Ss were also the highest and most consistent performers during the second extinction phase.

\section{Discussion}

The results reveal that the present experimental arrangement generated behavior which was highly resistant to extinction despite the occurrence of highly noxious punishment. Increasing the punishment frequency did not appreciably alter these effects until the avoidance contingency was completely withdrawn. Apparently, interspersing a punished extinction requirement within an active avoidance situation, while providing no differential cues between the two contingencies, results in durable exposure to highly punishing consequences. Such effects appear to have implications for certain forms of maladaptive behavior (Sandler, 1964).

\section{References}

Appel, J. B. Some schedules involving aversive control. J. exp. Anal. Behav., 1960, 3, 349-359.

Sandler, J. Masochism: An empirical analysis. Psychol. Bull., 1964, 62, 197-204.

Sandler, J., Davidson, R. S., Greene, W. E., \& Holzschuh, R. D. Effects of punishment intensity on instrumental avoidance behavior. J. comp. physiol. Psychol., 1966a, 61, 212-216.

Sandler, J., Davidson, R. S., \& Holzschuh, R. D. Effects of increasing punishment frequency on Sidman avoidance behavior. Psychon. Sci., 1966b, 5, 103-104.

Sidman, M. Some notes on "bursts" in free-operant avoidance experiments. J. exp. Anal. Behav., 1958, 1, 167-172.

Sidman, M., Herrnstein, R. J., \& Conrad, D. J. Maintenance of avoidance behavior by unavoidable shocks. J. comp. physiol. Psychol., 1957, 50, 553-557.

\section{Nofe}

1. This research was supported by Grant Number MH 06581 from the National Institute of Mental Health. 